\title{
Biogenic silver nanoparticles: efficient and effective antifungal agents
}

\author{
Vasudeva Reddy Netala ${ }^{1}$. Venkata Subbaiah Kotakadi ${ }^{2} \cdot$ Latha Domdi $^{1}$ • \\ Susmila Aparna Gaddam ${ }^{3}$ Pushpalatha Bobbu ${ }^{1}$ - Sucharitha K. Venkata ${ }^{4}$ \\ Sukhendu Bikash Ghosh ${ }^{5} \cdot$ Vijaya Tartte $^{6}$
}

Received: 23 December 2014 / Accepted: 23 May 2015/Published online: 3 June 2015

(C) The Author(s) 2015. This article is published with open access at Springerlink.com

\begin{abstract}
Biogenic synthesis of silver nanoparticles (AgNPs) by exploiting various plant materials is an emerging field and considered green nanotechnology as it involves simple, cost effective and ecofriendly procedure. In the present study AgNPs were successfully synthesized using aqueous callus extract of Gymnema sylvestre. The aqueous callus extract treated with $1 \mathrm{nM}$ silver nitrate solution resulted in the formation of AgNPs and the surface plasmon resonance (SPR) of the formed AgNPs showed a peak at $437 \mathrm{~nm}$ in the UV Visible spectrum. The synthesized AgNPs were characterized using Fourier transform infrared spectroscopy (FTIR), Transmission electron microscopy (TEM), and X-ray diffraction spectroscopy (XRD). FTIR spectra showed the peaks at 3333, 2928, $2361,1600,1357$ and $1028 \mathrm{~cm}^{-1}$ which revealed the role
\end{abstract}

Venkata Subbaiah Kotakadi

kotakadi72@gmail.com

$\triangle$ Vijaya Tartte

tvijayasvu@yahoo.com

1 Department of Biotechnology, Sri Venkateswara University, Tirupati, AP, India

2 Research Scientist, DST PURSE Centre, S.V. University, Tirupati, AP, India

3 Department of Virology, Sri Venkateswara University, Tirupati, AP, India

4 Department of Home Science, Sri Venkateswara University, Tirupati, AP, India

5 Nuclear Agriculture and Biotechnology Division, BARC, Mumbai, MH, India

6 Department of Botany, S.V. University, Tirupati, AP, India of different functional groups possibly involved in the synthesis and stabilization of AgNPs. TEM micrograph clearly revealed the size of the AgNPs to be in the range of 3-30 nm with spherical shape and poly-dispersed nature; it is further confirmed by Particle size analysis that the stability of AgNPs is due its high negative Zeta potential $(-36.1 \mathrm{mV})$. XRD pattern revealed the crystal nature of the AgNPs by showing the braggs peaks corresponding to (111), (200), (220) and (311) planes of face-centered cubic crystal phase of silver. Selected area electron diffraction pattern showed diffraction rings and confirmed the crystalline nature of synthesized AgNPs. The synthesized AgNPs exhibited effective antifungal activity against Candida albicans, Candida nonalbicans and Candida tropicalis.

Keywords Biogenic synthesis - Silver nanoparticles · FTIR $\cdot$ TEM $\cdot$ Antifungal activity

\section{Introduction}

Nanotechnology is a broad area and has shed a ray of light on biotechnology and medicine fields too. Especially, noble metal nanoparticles with fascinating colors due to the excitation of surface plasmon vibrations and optical properties offer a very convenient surface bioconjugation with molecular probes (Kreibig and Vollmer 1995; El-Sayed 2001). Most notable among them, use of silver in medical preparations is known since Neolithic age. However, the first recorded medical use of silver traces back to the eighth century (Moyer 1965). As the nanotechnology advances, silver races upfront in recent times due to its tunable photophysical attributes, its property being efficiently addressed via optical and spectroscopic techniques. Silver 
nanoparticles (AgNPs) now occupy the broader scientific interest from photonics to biomedicine.

Silver nanoparticles find innumerable applications due to their remarkable physicochemical properties which include optical, thermal (Karimzadeh and Mansour 2010), electronic, magnetic (Cobley et al. 2009; Feiner 2006) and catalytic properties (Edison and Sethuraman 2012). AgNPs have been found to possess different applications such as optical receptors (Vilchis et al. 2008), electric batteries (Wang et al. 2010), catalysts in many chemical reactions (Campelo et al. 2009), SERS based enzyme catalysis (Wei et al. 2007), biosensors (Dubas and pimpan 2008; Schultz et al. 2000), DNA delivery (Chen et al. 2012), antioxidants (Mittal et al. 2006), anticancer (Jacob et al. 2011), and antimicrobial agents (Jaidev and Narasimha 2010; Netala et al. 2014a, b). AgNPs as antimicrobial agents are of great interest today due to the increasing tendency of microbes to develop either resistance against antibiotics and transform themselves to resistant strains (Rai et al. 2009). For instance, Candida albicans and Candida nonalbicans are fungal pathogens of immuno-compromised host that produce a broad spectrum of diseases, ranging from chronic mucocutaneous candidiasis to invasive illnesses, such as systemic candidiasis, hepatosplenic candidiasis and peritonitis (Singhi and Deep 2009). Treating infections caused by Candida species has become a hectic problem due to its resistance to the less toxic azole drugs (Fluconoazole and Voriconazole) (White et al. 2002). Polyenes (Amphotericin B and Nystatin) cannot be employed because they are highly toxic and produce serious side effects like liver and renal dysfunction (Hoeharner et al. 2010). Hence researchers have been investigating and found metal nanoparticles, especially AgNPs, as alternate antimicrobial agents.

Silver nanoparticles can be synthesized by various physical and chemical methods including radiation-assisted (Huang et al. 2009; Abbasi et al. 2012), microwave-assisted (Nadagouda et al. 2011), electrochemical (Hosseini and Momeni 2010) photochemical (Kutsenko and Granchak 2009) polyol (Byeon and Kim 2012) and polyaniline processes (Bouazza et al. 2009). But most of these methods involved the application of toxic, hazardous and costly materials. Ecological impact and safety being considered the utmost objectives of any sort of research, nowadays, biological molecules and methods form the meat of it. Hence, the supramolecular complexes of bio-macromolecules and their electrostatic and topographic properties are being used widely in pharmaceutical and medical research areas. Peptides to proteins, Nucleic acids, sugars to polysaccharides, viral particles, plant derived compounds, etc., are being constantly explored for synthesis of novel nanoparticles and carriers. Hence the biological methods for the synthesis of AgNPs have gained significant interest in the field of nanobiotechnology. Biological methods involve the synthesis of clean, non-toxic, biocompatible and eco-friendly AgNPs. The biological methods, particularly plant-based approaches, do not involve hazardous chemicals, high-energy requirements and wasteful purifications (Vijayaraghavan et al. 2012; Venkatesham et al. 2014). A number of plant extracts including Andrographis Paniculata (Kotakadi et al. 2014a, b), Azadirachta indica (Tripathy et al. 2009), Cassia alata (Gaddam et al. 2014), Cathranthus roseus (Kotakadi et al. 2013), Centella asiatica (Netala et al. 2014a, b), Coleus aromaticus (Kotakadi et al. 2014a, b), Melia dubia (Netala et al. 2014a, b), Ocimum tenuiflorum (Patil et al. 2012), and Pulicaria glutinosa (Khan et al. 2014) have been reported.

Gymnema sylvestre is a woody climber belonging to the Asclepiadaceae family. It is mainly distributed in India, Srilanka, China, Japan and Australia. The leaves of this plant, popularly known as 'Gur-mar' in India, are renowned for distinctive property of suppressing the taste of sweetness. Hence the leaves of the G. sylvestre have been used for the treatment of diabetes in India since ancient times (Agarwal et al. 2000). Many scientists proved the antidiabetic property of $G$. sylvestre leaf extract both in mouse and human (Chattopadhyay 1999; Okabayashi et al. 1990). The mechanisms of antidiabetic property of leaf extract includes reduction of blood glucose levels by stimulation of insulin release (Sugihara et al. 2000), inhibition of glucose absorption (Hirata et al. 1992) and increased glucose tolerance (Kar et al. 1999). The leaf extract of this plant reduces elevated serum lipids, total cholesterol, and high-density lipoproteins and hence it is considered as anti-hyperlipidemic (Rachh et al. 2010). The leaves also possess hepatoprotective (Rana and Avadhoot 1992), anti-inflammatory, free radical scavenging and antioxidant properties (Nadkarni 1992; Agarwal et al. 2000). Besides, this the plant is also used in the treatment of hemorrhoids, jaundice, bronchitis (Masayuki et al. 1997), cardiopathy, asthma, dyspepsia, constipation and snake bite (Nadkarni 1992; Selvanayagam et al. 1995). Due to these wide medicinal values, the plant is called as "Miracle fruit plant". The pharmacological and biological activities of the $G$. sylvestre are mainly attributed to the active bioactive compounds present in the leaves including triterpene saponins belonging to oleanane and dammarene classes which are glycosides containing many hydroxyl groups, polyphenols including flavones, d-quercitol, lupeol, gymnemasides, gymnemagenols, and other constituents including oleanoleates, butyric acid, stigma sterols, tartaric acids, butyric acid, phytins, resins, various proteins, amino acids and their derivatives (Rao and sinsheimer 1971; Sahu et al. 1996). The total oleanane type saponin fraction of the leaves commonly known as 'gymnemic acids' have antidiabetic (Bakrudeen et al. 2010; Masayuki et al. 1997), 
anti-hyperlipidemic (Rachh et al. 2010), anti-inflammtory, antioxidant (Diwan et al. 1995) and anti-atherosclerotic activities (Bishayee and Chatterjee 1994). Development of in vitro callus cultures from the leaves is identified as alternative and very effective approach for the optimization of bioactive compounds (Kanetkar et al. 2006). This callus cultures are explored for the biosynthesis of AgNPs as another important pharmaceutical or biomedical application of $G$. sylvestre. In the present study, we report for the first time the successful synthesis of AgNPs from the aqueous callus extract of $G$. sylvestre. The synthesized AgNPs are well characterized by spectral analysis using different spectroscopic techniques. The synthesized AgNPs were evaluated for biomedical applications by checking antifungal activity against different Candida species.

\section{Materials and methods}

\section{Collection and sterilization of plant material}

Healthy plants of Gymnema sylvestre were collected from Tirumala hill region of Eastern Ghats, Andhra Pradesh, India. The plants were authenticated by Taxonomist, Department of Botany, Sri Venkateswara University, Andhra Pradesh, India. In this study the fresh, young and healthy leaves were used as explants. Leaves were excised and thoroughly washed with sterilized double distilled water (SDDW) for $5 \mathrm{~min}$ to remove the dust. Then the leaves were surface sterilized using $70 \%$ ethanol for 3 min. Finally, the leaves were rinsed with SDDW for 5 min and blotted on sterile paper to remove water drops.

\section{Induction of callus culture}

The sterilized leaves were cut into small fragments of size $0.6 \times 0.8 \mathrm{~cm}$. The leaf fragments were inoculated on Murashig-Skoog media supplied with 2,4-dichlorophenoxyaceticacid $\left(2.0 \mathrm{mg} \mathrm{L}^{-1}\right)$ and Kinetin $\left(1.0 \mathrm{mg} \mathrm{L}^{-1}\right)$ as callus promoting plant growth hormones (Bakrudeen et al. 2010; Murashige and Skoog 1962) The cultures were maintained at $23-25^{\circ} \mathrm{C}$ under the photoperiod of $16 \mathrm{~h}$ light/8 h dark.

\section{Preparation of aqueous callus extracts}

Fresh callus was collected in the Petri-dishes and dried at $40{ }^{\circ} \mathrm{C}$ for about $24 \mathrm{~h}$. The dried callus was crushed into very fine powder. $10 \mathrm{gm}$ of callus powder was boiled in $100 \mathrm{~mL}$ of SDDW for $15-20 \mathrm{~m}$ at $70{ }^{\circ} \mathrm{C}$ and then cooled to room temperature. This aqueous solution was filtered by Whatman no. 1 filter paper. The filtrate was named aqueous callus extract and used for the synthesis of AgNPs.

\section{Biogenic synthesis of AgNPs}

Silver nitrate $\left(\mathrm{AgNO}_{3}\right)$ was purchased from Himedia. Aqueous solution of $1 \mathrm{mM} \mathrm{AgNO}_{3}$ was prepared and used for the synthesis of AgNPs. $10 \mathrm{~mL}$ of aqueous callus extract was added to $90 \mathrm{~mL}$ of $1 \mathrm{mM} \mathrm{AgNO}_{3}$ solution in a 250-mL flask and incubated at room temperature in dark condition for about $24 \mathrm{~h}$ or until the solution turned dark brown in color. The synthesis of AgNPs was primarily detected by observing the solution for color change from yellow to dark brown.

\section{Characterization of AgNPs}

The synthesis of AgNPs was confirmed using UV-visible spectrophotometer 2060+ (Analytical Technologies Ltd,) with a resolution of $1 \mathrm{~nm}$ between 200 and $700 \mathrm{~nm}$. After the biosynthesis, the AgNPs were separated by centrifugation of the solution at $15000 \mathrm{rpm}$ for $15 \mathrm{~min}$. AgNPs were redispersed in water and purified by repeated centrifugation for five times to remove the unused callus extract and the pellet obtained was dried in hot air oven. Further, the air-dried powder of AgNPs was used for characterization. FTIR analysis of the purified AgNPs was carried out to study the possible functional groups involved in synthesis and stabilization of AgNPs. The analysis was done using FTIR (Model: ALPHA interferometer, Bruken,) in the range of $500-4000 \mathrm{~cm}^{-1}$ with the resolution of $2 \mathrm{~cm}^{-1}$. The size and shape of the AgNPs were determined using transmission electron microscopy (TEM). TEM analysis was carried out using FEI Tecnai F12 (Philips Electron Optics Ltd) operated at $100 \mathrm{kV}$. Particle size and Zeta potential measurement experiments were carried out using a Nanopartica (HORIBA instrument). XRD analysis was carried out to reveal the crystalline nature of synthesized AgNPs using Ultima IV X-ray diffractometer (Rigaku Ltd, Tokyo).

\section{Antifungal activity of AgNPs}

Disc diffusion method was employed to evaluate the antifungal activity of AgNPs against Candida albicans, Candida nonalbicans and Candida tropicalis (Kumar et al. 2013; Monali et al. 2009). $200 \mu \mathrm{L}$ of fungal inoculum was spread evenly on the surface of Potato Dextrose Agar (PDA) plates. Each PDA plate consists of four discs. To compare the antifungal activity of synthesized AgNPs, one sterile disc impregnated with less toxic azole drug, voriconazole and another sterile disc impregnated with toxic polyene, amphotericin B were used as positive controls. Sterile disc impregnated with $25 \mu \mathrm{L}(1 \mathrm{mg} / 1 \mathrm{~mL})$ of AgNPs was used as tested concentration. The plates were then incubated at $28{ }^{\circ} \mathrm{C}$ for $24 \mathrm{~h}$. After the incubation, the 
plates were examined for growth inhibition zones. The diameter of zone of inhibition (ZOI) was measured using ruler and recorded. The test was repeated three times to ensure reliability.

\section{Results and discussion}

In the present experiment, biogenic synthesis of AgNPs using aqueous callus extract of $G$. sylvestre was carried out followed by their characterization and antifungal activity. Callus was initiated on 12 th day of inoculation on

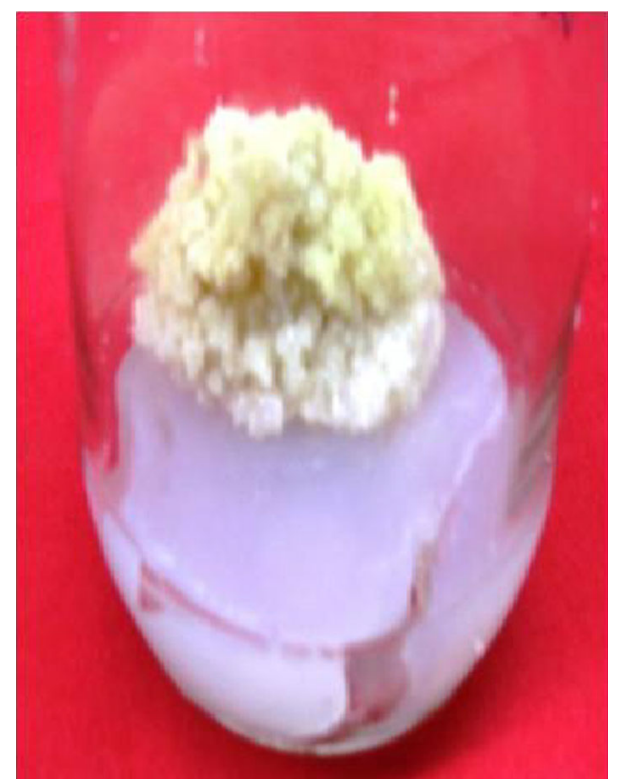

Fig. 1 Friable and light yellow color callus raised from the leaves of Gymnema sylvestre on MS media containing 2,4-dichlorophenoxyaceticacid $\left(2.0 \mathrm{mg} \mathrm{L}^{-1}\right)$ and kinetin $\left(1.0 \mathrm{mg} \mathrm{L}^{-1}\right)$

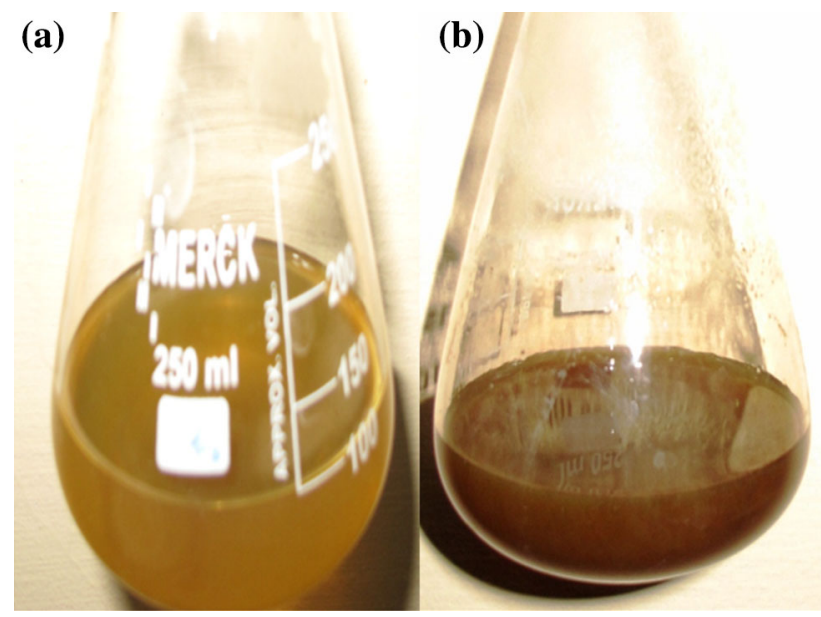

Fig. 2 Yellow color of the aqueous callus extract of the G. sylvestre exposed to $\mathrm{AgNO}_{3}$ (a) and dark brown color of the solution after $24 \mathrm{~h}$ of incubation indicates the of bioreduction (b)
Murashig-Skoog media supplied with 2,4-dichlorophenoxyaceticacid $\left(2.0 \mathrm{mg} \mathrm{L}^{-1}\right)$ and Kinetin $\left(1.0 \mathrm{mg} \mathrm{L}^{-1}\right)$ and good amount of callus biomass was observed between 20 and 35 days. After 35 days, the friable and light yellow colored callus (Fig. 1). was harvested and used for the preparation of the aqueous callus extract which is rich in plant secondary metabolites and proteins responsible for the bioreduction process. Hence this aqueous callus extract was used for biogenic synthesis of AgNPs. Initial confirmation of the bioreduction of $\mathrm{Ag}^{+}$(silver ions) to $\mathrm{Ag}^{0}$ (AgNPs) was done by observing the color change of the solution from yellow to dark brown (Fig. 2). It is well known that AgNPs exhibit a dark brown or yellowish brown color in aqueous solution due to excitation of characteristic surface plasmon vibrations (Kreibig and Vollmer 1995; Prathna et al. 2011). The bioreduction was further confirmed by UV-vis spectroscopy.

\section{UV-vis analysis}

The UV-visible spectra (Fig. 3) of the reaction solution showed an absorbance peak at $437 \mathrm{~nm}$ which is characteristic surface plasmon resonance (SPR) peak of AgNPs and hence confirmed their synthesis. The sharp and strong absorption peak is due to surface plasmon vibrations in the visible region ofexcited AgNPs. It is known that the size and shape of the nanoparticles reflect the absorbance peak. In fact the size has a linear correlation with the peak intensity, while the number of nanoparticles does not have such linear correlation (Jaidev and Narasimha 2010). SPR peak could correspond to the spherical shape of metal nanoparticles (Kotakadi et al. 2014a, b, 2015). Different metabolites and proteins present in the aqueous callus extract could be responsible for bioreduction and capping of AgNPs synthesized (Noginov et al. 2007; Stamplecoskie and Scaiano 2010).

\section{FTIR spectra analysis}

The FTIR spectral analysis of AgNPs (Fig. 4). showed intensive peaks at 3333, 2928, 2361, 1600, 1357 and $1028 \mathrm{~cm}^{-1}$, respectively. The sharp peak at $3333 \mathrm{~cm}^{-1}$ can be assigned to $\mathrm{N}-\mathrm{H}$ stretching of the primary amines and the peak at $2928 \mathrm{~cm}^{-1}$ corresponding to $\mathrm{C}-\mathrm{H}$ stretching of methylene groups of the protein (Bozanic et al. 2010). The peak at $2361 \mathrm{~cm}^{-1}$ could be assigned to $\mathrm{N}-\mathrm{H}$ stretching or $\mathrm{C}-\mathrm{O}$ stretching vibrations (Ashok et al. 2010). Peak at $1600 \mathrm{~cm}^{-1}$ corresponds to asymmetrical $\mathrm{C}-\mathrm{O}$ stretching (Kora et al. 2012). The Peak observed at $1357 \mathrm{~cm}^{-1}$ corresponds to $\mathrm{C}-\mathrm{N}$ stretching vibrations of aromatic amines and aliphatic amines (Sanghi and Verma 2009). The peak at $1028 \mathrm{~cm}^{-1}$ is responsible for $\mathrm{O}-\mathrm{H}$ deformation/C-O stretch of phenolic and alcoholic groups (Valentina and 
Fig. 3 UV/vis spectra showing characteristic surface plasmon resonance peak of AgNPs synthesized using aqueous callus extract of $G$. sylvestre
Fig. 4 FTIR spectra of the biogenic synthesized AgNPs using aqueous callus extract of G. sylvestre
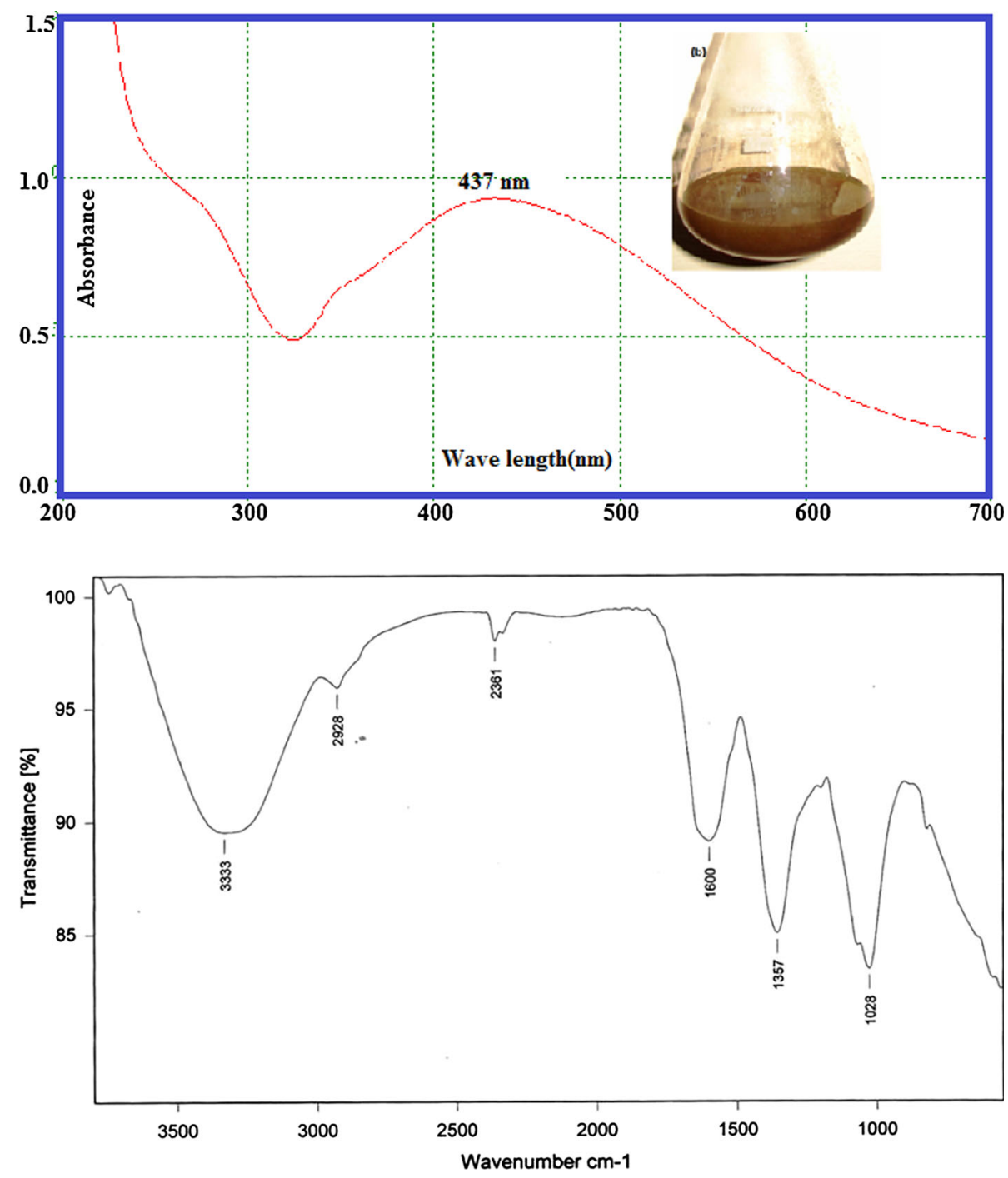

Boris 2013). FTIR analysis clearly revealed that phytochemicals like polyphenols present in the callus extract were mainly responsible for reduction of silver ions $\left(\mathrm{Ag}^{+}\right)$ into nanoscale silver particles $\left(\mathrm{Ag}^{0}\right)$. Proteins could play the main role in the stabilization of AgNPs by acting as capping agents.

\section{TEM analysis and SAED pattern}

TEM studies determined the size and shape of the AgNPs synthesized. From the TEM micrograph it is clear that AgNPs are polydispersed, spherical in shape and ranged in size from 3 to $30 \mathrm{~nm}$. TEM micrograph of AgNPs at different scale bars is represented in Fig. 5. The AgNPs in the solution were partially aggregated, uniform in size and stable. The TEM results were consistent with many reports for plant and plant-derived extract-mediated synthesis of AgNPs (Netala et al. 2014a, b; Kotakadi et al. $2014 a$, b). Figure $5 b$ shows the SAED pattern of synthesized AgNPs, indicating polycrystalline diffraction rings which could be indexed to cubic-lattice of metallic silver and reveals the synthesized AgNPs are crystalline metallic silver.

\section{Particle size determination}

The particle size of the biosynthesized AgNPs was detected by intensity and laser diffraction which are poly-dispersed in mixture solution. The average size (hydro dynamic radius) of synthesized AgNPs was found to be $25.3 \mathrm{~nm}$ with callus extract (Fig. 6i); after the analysis of AgNPs with callus extract, it has been revealed that the particles synthesized with aqeous callus extract are less than 3-30 $\mathrm{nm}$ in size. The results are similar to that of TEM results indicating that the average size of the AgNPs is $25.3 \mathrm{~nm}$. The biosynthesized particles are poly-dispersed in nature. The stability was further confirmed by Zeta potential of the particles. 
Fig. 5 TEM micrograph of biogenic synthesized AgNPs; scale bar represents $50 \mathrm{~nm}(\mathbf{a})$; $20 \mathrm{~nm}(\mathbf{b}) ; 10 \mathrm{~nm}(\mathbf{c})$. SAED pattern of the AgNPs (d)
Fig. 6 Particle size analysis for AgNPs of callus extract
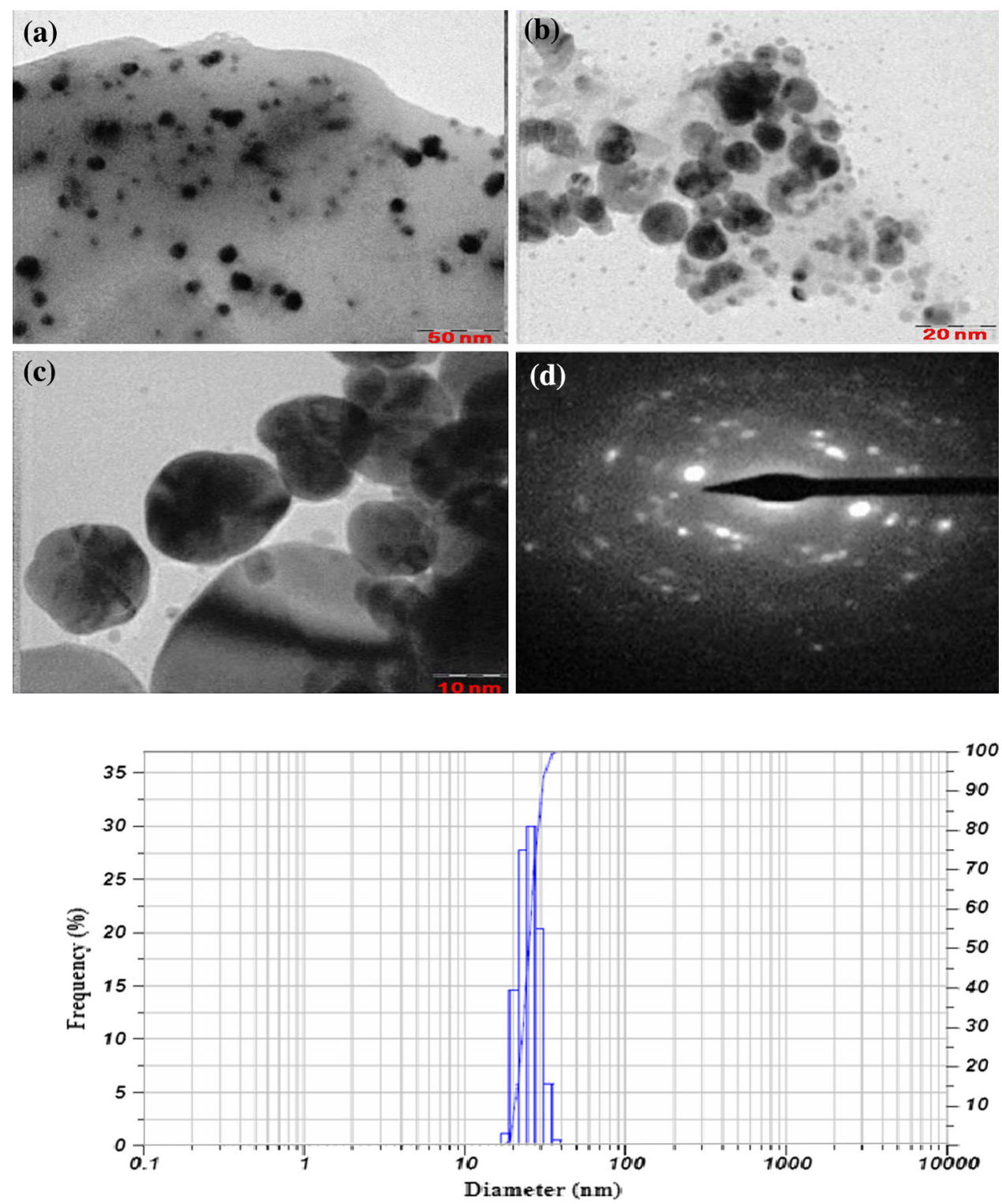

Calculation Results

\begin{tabular}{|c|c|c|c|c|}
\hline Peak No. & S.P.Area Ratio & Mean & S. D. & Mo.de \\
\hline 1 & 1.00 & $25.3 \mathrm{~nm}$ & $3.6 \mathrm{~nm}$ & $25.4 \mathrm{~nm}$ \\
\hline 2 & -- & $--\mathrm{nm}$ & $--\mathrm{nm}$ & $-\mathrm{nm}$ \\
\hline 3 & -- & $--\mathrm{nm}$ & $--\mathrm{nm}$ & $-\mathrm{nm}$ \\
\hline Tatal & 1.00 & $25.3 \mathrm{~nm}$ & $3.6 \mathrm{~nm}$ & $25.4 \mathrm{~nm}$ \\
\hline
\end{tabular}

\section{Zeta potential of AgNPs}

The electrostatic repulsive force between the nanoparticles depends on the charge which is present on the surface of the nanoparticle. When they are negatively charged, the process prevents the nanoparticles from agglomeration in the medium, leading to long-term stability. In the present study, the very high negative value of Zeta potential confirms the repulsion among the particles and thereby increases the stability of the formulation. The zeta potential of the AgNPs of fruit extract was found to be $-36.1 \mathrm{mV}$.
(Fig. 7) Based on the above results, it is concluded that the AgNPs synthesized with callus extract were very stable.

\section{XRD analysis}

XRD is used to evaluate the crystalline nature of synthesized AgNPs. XRD pattern obtained (Fig. 8) showed that four characteristic diffraction peaks at $38.31^{\circ}, 44.61^{\circ}, 64.5^{\circ}$ and $77.58^{\circ}$ were, respectively, indexed to (111), (200), (220) and (311) planes of face-centered cubic crystal lattice of silver (JCPDS PDF card 87-0718). XRD pattern showed 
Fig. 7 Zeta potential of synthesized AgNPs by callus extract
Fig. 8 XRD pattern of biogenic synthesized AgNPs using aqueous callus extract of $G$. sylvestre
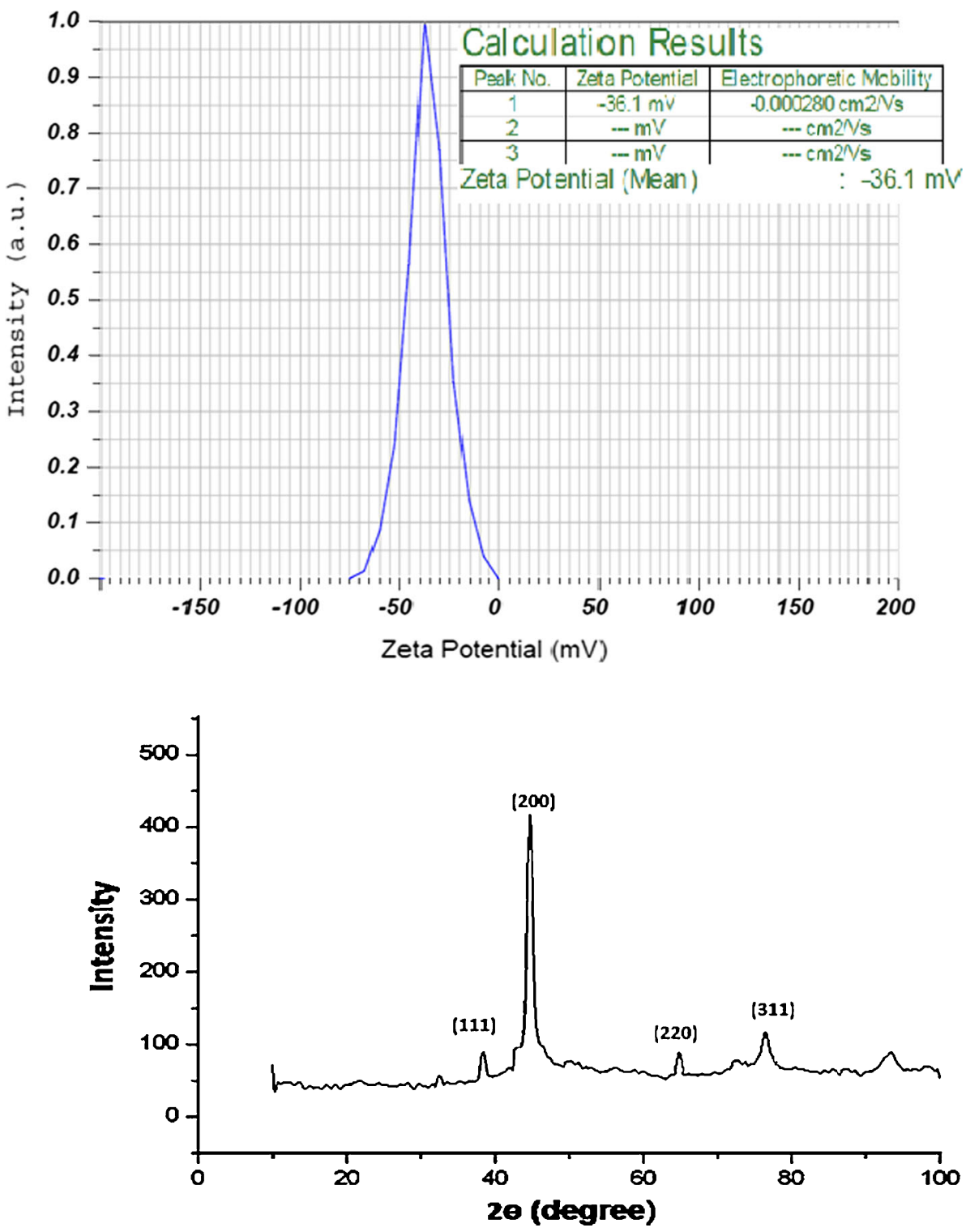

here are consistent with the earlier reports (Patil et al. 2012; Vijayaraghavan et al. 2012).

\section{Antifungal activity}

To reveal the biomedical importance of the synthesized AgNPs antifungal activity was carried out against $C$. albicans, C. nonalbicans and C. tropicalis. The synthesized AgNPs exhibited excellent antifungal activity against $C$. albicans, $C$. nonalbicans and $C$. tropicalis and formed the ZOI of diameters 15.4, 14.2 and $15.7 \mathrm{~mm}$, respectively (Fig. 9). Although, AgNPs showed strong antifungal activity against all the candida species, higher ZOI was noticed for $C$. tropicalis followed by $C$. albicans. Remarkably, AgNPs exhibited almost equal activity with that of voriconazole but showed less activity than the toxic drug Amphotericin B (Table 1). The results suggested that the antifungal activity of AgNPs can be further enhanced by increasing their concentration as these are nontoxic and biocompatible. The results of antifungal activity of the AgNPs are consistent with many earlier reports (Kumar et al. 2013; Monali et al. 2009) and proved that the biosynthesized AgNPs possess more potent antifungal activity when increasing the concentrations than the azole drugs which are toxic at higher concentrations and also provided the information on the mode of action of AgNPs on fungi (Kumar et al. 2013; Monali et al. 2009; Bankar et al. 2010; Kim et al. 2009; Vivek et al. 2011). AgNPs perturb the cell wall and result in the release of cell wall components like ions and intracellular proteins and as a result the growth of fungi is inhibited (Kim et al. 2009). In addition, they form pore-like structures or pits and dissipate the membrane electrical potential. As a result disruption of cell membrane occurs which in turn inhibits the normal budding process (Bankar et al. 2010; Kim et al. 2009; Vivek et al. 2011).

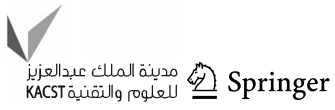


Fig. 9 Antifungal activity of the AgNPs against Candida albicans (a), Candida nonalbicans (b) and Candida tropicalis $(\mathbf{c})$. No inhibition zone is observed by aqueous callus extract $(i)$, Inhibition zones formed by AgNPs (ii), by Amphotericin B (iii) and by voriconazole $(i v)$ were represented
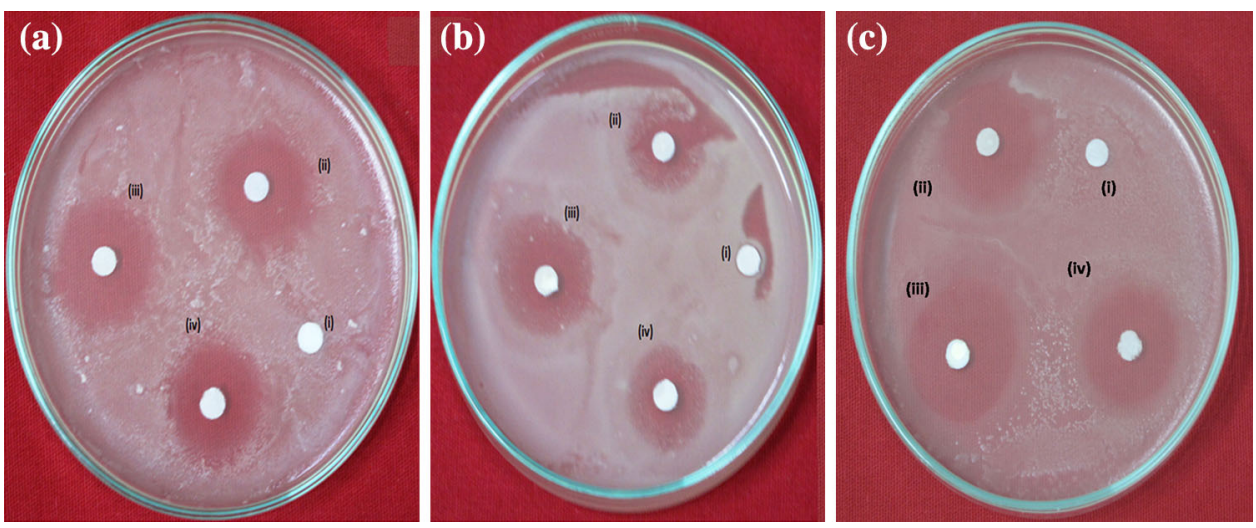

Table 1 Antifungal activity of biogenic synthesized AgNPs compared with amphotericin B and Voriconazole

\begin{tabular}{lllll}
\hline S. no & Tested fungi & Amphotericin B & Voriconazole & AgNPs \\
\hline 1. & C. albicans & 16.1 & 15.4 & 15.2 \\
2. & C. nonalbicans & 14.8 & 13.4 & 12.9 \\
3. & C. tropicalis & 16.8 & 16.2 & 15.8 \\
\hline
\end{tabular}

Values are expressed as diameter of zone of inhibition (ZoI)

\section{Conclusion}

In the present study, we have developed a novel, promising, ecofriendly and biotechnological approach for the synthesis of clean and biocompatible AgNPs. In this study, we have synthesized spherical shaped AgNPs of 3-30 nm in size using aqueous callus extract of $G$. sylvestre as a reducing agent for the first time. The synthesized AgNPs are very well dispersed, well defined in shape and polycrystalline in nature. The synthesized AgNPs possess very good antifungal activity against different candida species and hence clearly proved their pharmaceutical and medicinal importance as tropical antifungal agents and in the manufacturing of antifungal skin ointments.

Acknowledgments We thank Nuclear Agriculture and Biotechnology Division (NABTD), DAE-BRNS, BARC, Mumbai, India, for financial support and also are thankful to Indian institute of chemical technology (IICT), Hyderabad, AP, India, for technical support.

Conflict of interest The authors declare that there is no conflict of interest.

Open Access This article is distributed under the terms of the Creative Commons Attribution 4.0 International License (http:// creativecommons.org/licenses/by/4.0/), which permits unrestricted use, distribution, and reproduction in any medium, provided you give appropriate credit to the original author(s) and the source, provide a link to the Creative Commons license, and indicate if changes were made.

\section{References}

Abbasi AR, Kalantary H, Yousefi M, Ramazani A, Morsali A (2012) Synthesis and characterization of Ag nanoparticles @ polyethylene fibers under ultrasound irradiation. Ultrason Sonochem 19:853-857

Agarwal SK, Singh SS, Verma S, Lakshmi V, Sharma A, Kumar S (2000) Chemistry and medicinal uses of Gymnema sylvestre [Gur-Mar] leaves a review. Indian Drugs 37:354-360

Ashok B, Bhagyashree J, Ameeta RK, Smita Z (2010) Banana peel extract mediated novel route for the synthesis of silver nanoparticles. Colloids Surf A Physicochem Eng Aspects 368:58-63

Bakrudeen AAA, Rao AS, Rao MV (2010) In vitro callus and in vivo leaf extract of Gymnema sylvestre stimulate cells regeneration and anti-diabetic activity in Wistar rats. Phytomedicine 17:1033-1039

Bankar A, Joshi B, Kumar AR, Zinjarde S (2010) Banana peel extract mediated novel route for the synthesis of silver nanoparticles. Colloids Surf A 368:58-63

Bishayee A, Chatterjee M (1994) Hypolipidaemic and antiatherosclerotic effects of oral Gymnema sylvestre $\mathrm{R}$. Br. leaf extract in albino rats fed on a high fat diet. Phytothera Res 8:118-120

Bouazza S, Alonzo V, Hauchard D (2009) Synthesis and characterization of $\mathrm{Ag}$ nanoparticles-polyaniline composite powder material. Synth Metals 159:1612-1619

Bozanic DK, Trandafilovic LV, Luyt AS, Djokovic V (2010) Green synthesis and optical properties of silver-chitosan complexes and nanocomposites. React Function Polymers 70:869-873

Byeon JH, Kim YW (2012) A novel polyol method to synthesize colloidal silver nanoparticles by ultrasonic irradiation. Ultrason Sonochem 19:209-215 
Campelo JM, Luna D, Luque R, Marinas JM, Romero AA (2009) Sustainable preparation of supported metal nanoparticles and their applications in catalysis. Chem Sus Chem 2:18-45

Chattopadhyay RR (1999) A comparative evaluation of some blood sugar lowering agents of plant origin. $\mathrm{J}$ Ethanopharmocol $67: 367-372$

Chen XJ, Sanchez GBL, Qian ZX, Park SJ (2012) Noble metal nanoparticles in DNA detection and delivery. Wiley Interdisci Rev Nanomed Nanobiotech 4:273-290

Cobley CM, Skrabalak SE, Campbel DJ, Xia Y (2009) Shapecontrolled synthesis of silver nanoparticles for plasmonic and sensing applications. Plasmonics 4:171-179

Diwan PV, Margaret I, Ramakrishna S (1995) Influence of Gymnema sylvestre on inflammation. Inflammo pharmacology 3:271-277

Dubas ST, Pimpan V (2008) Green synthesis of silver nanoparticles for ammonia sensing. Talanta 76:29-33

Edison T, Sethuraman M (2012) Instant green synthesis of silver nanoparticles using Terminalia chebula fruit extract and evaluation of their catalytic activity on reduction of Methylene Blue. Proc Biochem 47:1351-1357

El-Sayed MA (2001) Some interesting properties of metals confined in time and nanometer space of different shapes. Acc Chem Res $34: 257-264$

Feiner LF (2006) Nanoelectronics: crossing boundaries and borders. Nat Nano 1:91-92

Gaddam SA, Kotakadi VS, Gopal DVRS, Rao YS, Reddy AV (2014) Efficent and robust biofabrication of silver nanoparticles by cassia alata leaf extract and their antimicrobial activity. J Nano Chem 4:1-9

Hirata S, Abe T, Imoto T (1992) Effect of crude gymnemic acid on oral glucose tolerance test in human being. J Yonago Med Assoc 43:392-396

Hoeharner CF, Cummings ED, Hilliard GM, Rogers PD (2010) Changes in the proteome of Candida albicans in response to azole, polyene and echinocandin. Antimicrob Agents Chemother 54:1655-1664

Hosseini M, Momeni MM (2010) Silver nanoparticles dispersed in polyaniline matrixes coated on titanium substrate as a novel electrode for electro-oxidation of hydrazine. J Mater Sci 45:3304-3310

Huang NM, Radiman S, Lim HN, Khiew PS, Chiu WS, Lee KH, Syahida A, Hashim R, Chia CH (2009) Gammaray assisted synthesis of silver nanoparticles in chitosan solution and antibacterial properties. Chem Eng J 155:499-507

Jacob S, Finub J, Narayanan A (2011) Synthesis of silver nanoparticles using Piper longum leaf extracts and its cytotoxic activity against Hep-2 cell line. Col Surf B Biointerf 91:212-214

Jaidev LR, Narasimha G (2010) Fungal mediated biosynthesis of silver nanoparticles, characterization and antimicrobial activity. Col Surf B Biointerf 81:430-433

Kanetkar PV, Singhal RS, Laddha KS, Kamat MY (2006) Extraction and quantification of gymnemic acids through gymnemagenin from callus cultures of Gymnema sylvestre. Phytochem Anal 17:409-413

Kar A, Choudhary BK, Bandyopadhyay NG (1999) Preliminary studies of the inorganic constituents of some indigenous hypoglycaemic herbs on oral glucose tolerance test. J Ethnopharmacol 64:179-184

Karimzadeh R, Mansour N (2010) The effect of concentration on the thermo-optical properties of colloidal silver nanoparticles. Opt Laser Technol 42:783-789

Khan M, Khan ST, Merajuddin K, Adil SF, Javed M, Abdulaziz AK, Abdulrahman A, Mohammed R, Siddiqui H, Hamad ZA (2014) Antibacterial properties of silver nanoparticles synthesized using Pulicaria glutinosa plant extract as a green bioreductant. Int $\mathrm{J}$ Nanomed 9:3551-3565
Kim KJ, Sung WS, Suh BK, Moon SK, Choi JS, Kim JG, Lee DG (2009) Antifungal activity and mode of action of silver nanoparticles on Candida albicans. Biometals 22:235-242

Kora AJ, Sashidhar RB (2012) Arunachalam, J (2012) Aqueous extract of gum olibanum (Boswellia serrata): a reductant and stabilizer for the biosynthesis of antibacterial silver nanoparticles. Process Biochem 47:1516-1520

Kotakadi VS, Rao YS, Gaddam SA, Prasad TNVKV, Reddy AV, Gopal DVRS (2013) Simple and rapid biosynthesis of stable silver nanoparticles using dried leaves of Catharanthus roseus. Linn. G. Donn and its anti microbial activity. Colloids Surf B Biointerfaces 105:194-198

Kotakadi VS, Aparna GS, Rao YS, Prasad TNVKV, Reddy AV, Gopal DVRS (2014a) Biofabrication of silver nanoparticles using Andrographis paniculata. Eur J Med Chem 73:135-140

Kotakadi VS, Aparna GS, Sucharitha KV, Gopal DVRS (2014b) New generation of bactericidal silver nanoparticles against different antibiotic resistant Escherichia coli strains. Appl Nanosci. doi:10.1007/s13204-014-0381-7

Kotakadi VS, Aparna GS, Sucharitha K.Venkata, Prasad TNVKV, Saigopal DVR (2015) Ficus fruit-mediated biosynthesis of silver nanoparticles and their antibacterial activity against antibiotic resistant E.coli strains. Curr NanoSci 11:1-12. doi:10.2174/ 1573413711666150126225951

Kreibig U, Vollmer M (1995) Optical properties of metal clusters. Springer, Berlin, New York, pp 483-525

Kumar P, Senthamil SS, Govindaraju M (2013) Seaweed-mediated biosynthesis of silver nanoparticles using Gracilaria corticata for its antifungal activity against Candida spp. Appl Nanosci 3:495-500

Kutsenko AS, Granchak VM (2009) Photochemical synthesis of silver nanoparticles in polyvinyl alcohol matrices. Theo Exp Chem 45:313-318

Masayuki T, Yuhao L, Nobutoshi M, Johji Y, Masashi K, Hisashi M (1997) Medicinal food stuffs IX. The inhibitors of glucose absorption from the leaves of Gymnema sylvestre $\mathrm{R}$. Br. (Asclepiadaceae): structures of gymnemosides a and b. Chem Pharm Bull 45:1671-1676

Mittal AK, Kaler A, Banerjee UC (2006) Free radical scavenging and antioxidant activity of silver nanoparticles synthesized from flower extract of Rhododendron dauricum. Nano BioMed Eng 4:118-124

Monali G, Jayendra K, Avinash I, Aniket G, Mahendra R (2009) Fungus-mediated synthesis of silver nanoparticles and their activity against pathogenic fungi in combination with fluconoazole. Nanomedicine 5:382-386

Moyer CA (1965) Treatment of burns. Trans Stud Coll Phys Phila 33:53-103

Murashige T, Skoog F (1962) A revised medium for rapid growth and bioassays with tobacco tissue cultures. Physiol Plant 15:473-497

Nadagouda MN, Speth TF, Varma RS (2011) Microwave-assisted green synthesis of silver nanostructures. Acc Chem Res 44:469-478

Nadkarni AK (1992) Indian Materia Medica. In: Gymnema sylvestre: Popular Prakashan: Bombay, vol. 1. pp 596-597

Netala VR, Kotakadi VS, Nagam V, Bobbu P, Ghosh SB, Tartte V (2014a) First report of biomimetic synthesis of silver nanoparticles using aqueous callus extract of Centella asiatica and their antimicrobial activity. Appl Nanosci. doi:10.1007/s13204-014-0374-6

Netala VR, Kotakadi VS, Ghosh SB, Bobbu P, Nagam V, Sharma KK, Tartte V (2014b) Biofabrication of silver nanoparticles using aqueous leaf extract of Melia dubia, characterization and antifungal activity. Int J Pharm Pharm Sci 6:298-300

Noginov M, Zhu G, Bahoura M, Adegoke J, Small C, Ritzo BA, Drachav VP, Shalaev VM (2007) The effect of gain and

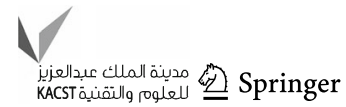


absorption on surface plasmons in metal nanoparticles. Appl Phys B 86:455-460

Okabayashi Y, Tani S, Fujisawa T, Koide M, Hasegawa H, Nakamura T, Fujii M, Otsuki M (1990) Effect of Gymnema sylvestre R.Br. on glucose homeostasis in rats. Diabetes Res Clin Pract 9:143-148

Patil RS, Kokate MR, Kolekar SS (2012) Bioinspired synthesis of highly stabilized silver nanoparticles using Ocimum tenuiflorum leaf extract and their antibacterial activity. Spec Acta Part A Mol Biomol Spec 91:234

Prathna TC, Chandrasekaran N, Raichur AM, Mukherjee A (2011) Biomimetic synthesis of silver nanoparticles by Citrus limon (lemon) aqueous extract and theoretical prediction of particle size. Colloids Surf B Biointerf 82:152-159

Rachh PR, Rachh MR, Ghadiya NR, Modi DC, Modi KP, Patel NM, Rupareliya MT (2010) Anti-hyperlipidemic activity of Gymnema sylvestre $\mathrm{R} . \mathrm{Br}$ leaf extract on rats fed with high cholesterol diet. Int J Pharmacol 6:138-141

Rai M, Yadav A, Gade A (2009) Silver nanoparticles as a new generation of antimicrobials. Biotechnol Adv 27:76-88

Rana AC, Avadhoot Y (1992) Experimental evaluation of hepatoprotective activity of Gymnema sylvestre and Curcuma zedoaria. Fitoterapia 63:60-62

Rao GS, Sinsheimer JE (1971) Constituents from Gymnema sylvestre leaves VIII: isolation, chemistry and derivatives of gymnemagenin and gymnestrgenin. J Pharma Sci 60:190-193

Sahu NP, Mahato SB, Sarkar SK, Poddar G (1996) Triterpenoid saponins from Gymnema sylvestre. Phytochemistry 41:1181-1185

Sanghi R, Verma P (2009) Biomimetic synthesis and characterisation of protein capped silver nanoparticles. Biores Technol 100:501-504

Schultz S, Smith DR, Mock JJ, Schultz DA (2000) Applications of silver nanoparticles in biosensor. Proc Natl Acad Sci USA 97:996

Selvanayagam ZE, Gnanavendhan SG, Chandrashekhran P, Balakrishna K, Rao RB (1995) Plants with anti-snake venom activitya review on pharmacological and clinical studies. Fitoterapia 65:99-111

Singhi S, Deep A (2009) Invasive candidiasis in pediatric intensive care units. Ind J Pediatr 76:1033-1044
Stamplecoskie KG, Scaiano JC (2010) Light emitting diode can control the morphology and optical properties of silver nanoparticles. J Am Chem Soc 132:1825-1827

Sugihara Y, Nojima H, Matsuda H, Murakami T, Yoshikawa M, Kimura I (2000) Antihyperglycemic effects of gymnemic acid $\mathrm{IV}$, a compound derived from Gymnema sylvestre leaves in streptozotocin-diabetic mice. J Asian Nat Prod Res 2:321-327

Tripathy A, Chandrasekaran N, Raichur AM, Mukherjee A (2009) Antibacterial applications of silver nanoparticles synthesized by aqueous extracts of Azadirachta indica (neem) leaves. J Biomed Nano 5:93-98

Valentina AL, Boris FM (2013) Spectroscopy study of silver nanoparticles fabrication using synthetic humic substances and their antimicrobial activity. Spectrochim Acta Part A Mol Biomol Spectrosc 108:115-122

Venkatesham M, Ayodhya D, Madhusudhan A, Babu NV, Veerabhadram G (2014) A novel green one-step synthesis of silver nanoparticles using chitosan: catalytic activity and antimicrobial studies. Appl Nano 4:113-119

Vijayaraghavan K, Nalini SPK, Prakash NU, Madhankumar D (2012) Biomimetic synthesis of silver nanoparticles by aqueous extract of Syzygium aromaticum. Mat Lett 75:33-35

Vilchis NAR, Sánchez MV, Camacho LMA, Gómez ERM, Arenas AJA (2008) Solvent less synthesis and optical properties of $\mathrm{Au}$ and Ag nanoparticles using Camellia sinensis extract. Mat Lett 62:3103-3105

Vivek M, Kumar PS, Steffi S, Sudha S (2011) Biogenic silver nanoparticles by Gelidiella acerosa extract and their antifungal effects. Avicenna J Med Biotechnol 3:143-148

Wang T, Kaempgen M, Nopphawan P, Wee G, Mhaisalkar S, Srinivasan M (2010) Silver nanoparticle decorated carbon nanotubes as bifunctional gas-diffusion electrodes for zinc-air batteries. J Pow Sources 195:4350-4355

Wei H, Li J, Wang Y, Wang E (2007) Silver nanoparticles coated with adenine: preparation, self-assembly and application in surface-enhanced Raman scattering. Nanotechnology $18: 610-615$

White TC, Holleman S, Dy F, Mirels LF, Stevens DA (2002) Resistance mechanism in clinical isolates of Candida albicans. Antimicrob Agents Chemother 46:1704-1713 